\title{
Transformation of nursing education: the experience of Bahrain
}

\author{
Muyssar Awadhalla, ${ }^{1}$ Batool Al-Mohandis ${ }^{2}$ and Fariba Al-Darazi ${ }^{3}$
}

${ }^{2}$ WHO Collaborating Center for Nursing Development, College of Health Sciences, University of Bahrain, Manama, Bahrain, (Correspondence to: M. Awadhalla: msabri@uob.edu.bh). ${ }^{2}$ Nursing Policy and Education Development, Manama, Bahrain. ${ }^{3}$ Nursing Consultant, Manama, Bahrain. Former Regional Advisor for Nursing, Midwifery and Allied Health Personnel, WHO Regional office for the Eastern Mediterranean, Cairo, Egypt.

\begin{abstract}
Nursing and midwifery education has developed significantly in Bahrain, and in particular the transformation that took place with the establishment of the College of Health Sciences in 1976. The institution played a pioneering role in national health professions education and meeting national and regional needs for nurses and midwives. This review aims to examine those strategies that enabled transformation of nursing education and the integration of contemporary nursing education models. Key to the transformation was development of a system of a competency based, student-centred educational programme; introduction of a balance between nursing's health-related and curative functions in the curriculum that broadened the scope of nursing's role; faculty development; active collaboration between education and nursing services in curriculum planning and implementation; and initiatives implemented to fund nursing education and to ensure the quality of the programmes. In 1984, only $15 \%$ of posts requiring a minimum registered nurse qualification were filled by Bahrainis. However, the rate of national nurses in the workforce has increased steadily, and today Bahrainis constitute $62 \%$ of the nursing workforce in the country. Thus, transformation of nursing education has been the pillar for shaping the nursing profession.
\end{abstract}

Keywords: nursing education, curriculum development, institutes and academies, capacity building, Bahrain

Citation: Awadhalla M; Al-Mohandis B; Al-Darazi F. Transformation of nursing education: the experience of Bahrain. East Mediterr Health J. 2018;24(9):959-964. https://doi.org/10.26719/2018.24.9.959

Received: 17/04/18; accepted: 06/09/18

Copyright (c) World Health Organization (WHO) 2018. Some rights reserved. This work is available under the CC BY-NC-SA 3.o IGO license (https:// creativecommons.org/licenses/by-nc-sa/3.o/igo).

\section{Introduction}

Like other countries in the Region, Bahrain has experienced major demographic, economic, social and technological changes in the past five decades. These changes have had direct and indirect impact on the health needs of individuals and families and community's expectations, as well as the health system in general.

Investment in the development of a national health workforce has been one of the most impressive achievements that has occurred in Bahrain's health system. One of the important approaches by the Ministry of Health to meet the need for a national health workforce was to develop strategies to transform health professions' education, including nursing and midwifery education, and to train more Bahraini nurses to meet the shortfall in the national workforce.

From its early inception, nursing and midwifery education in Bahrain continued on the path of reform. It was in the mid-1980s when a major curriculum reevaluation was made followed by the adoption of a series of innovative curriculum models. The focus of the reform was on nursing education structure, processes and outcomes. This article reviews development of nursing education in Bahrain, highlighting the transformation that took place with the establishment of the College of Health Sciences in 1976 and the role it played in meeting national and regional needs.

\section{Early years}

The first school of nursing in Bahrain was established in 1959, enrolling seven women in its formal nurse training programme and who had completed primary or intermediate school education as a requirement for entry. In 1968, the health department developed a plan for a comprehensive health programme, which included training programmes for Bahrainis in all health fields; establishment of a network of primary health care centres covering all the country; strengthening preventive medicine and developing a medical records department (1).

In 1970; the requirement for entering into nursing was raised to completion of secondary school education; and by 1973 the school was moved into a new building with better facilities for teaching and learning, the Yousif Bin Ahmed Kanoo School of Nursing (2).

The output from the School of Nursing from 1963 until 1978 was 147 nurses only. To address this situation, the government established the College of Health Sciences (CHS) in 1976 by amalgamating the Yousif Bin Ahmed Kanoo School of Nursing with CHS in order to facilitate the preparation of a range of nursing and allied health professionals. CHS was established in collaboration with the American University of Beirut, Lebanon, and this move had the effect of bringing nursing into the higher education system and full student status was conferred to nurses in training. 
Further progress was made in 1981 when the college embarked on a comprehensive system of nursing education characterized by a unifying curricular framework, which offered a career ladder that integrated the academic and professional dimension of nursing, and the educational model is fully described by Kronfol and Affara (1982) (3). During the same year, collaboration was established with the University of Illinois at Chicago, United States, to support faculty development and further develop the allied health and nursing programmes through the signing a memorandum of understanding between the two institutions.

The college founders had a desire to graduate health professionals who had mastered the set of competencies relevant to their professional roles. To reach this goal, a competency-based curriculum model - referred to as the professional performance situation model (PPSM) - was adopted for future educational planning (4). The main features of the new curriculum were its emphasis on identifying and planning for mastery of the necessary competencies namely identifying those abilities, skills, knowledge, judgments, attitudes and values required for effective role performance (5). Programmes that were developed or revised reflected this approach to educational planning, thus making the teaching and learning process student-centred. The other major shift was developing a conceptual framework that guided the nursing curricula by dealing with health as it did with illness; shifting from the medical model-based curriculum that focused on curative nursing functions to one that introduced a balance between nursing's health and curative functions. The scope of nursing was broadened to include not only the individual but also the family and the community. Furthermore, by making the problem-solving approach a common element in every nursing course and the nursing process a basic tool for practice, future graduates would be able to make sounder clinical judgments and apply systematic and rational approaches to the delivery of nursing care (6).

To ensure having qualified nursing and midwifery teachers, all novice nursing and allied health teachers had to undergo a one-year health professions education programme run by the educational development centre. The programme was established in the early 1980 os as part of a faculty development plan. In addition, Bahraini nursing faculty was sent abroad on government scholarships to obtain their doctorate and master's degrees in different specialties (7).

In 1984 , only $15 \%$ of posts requiring a minimum registered nurse qualification were filled by Bahrainis. However, the rate of national nurses in the workforce has increased steadily. In 1991, Bahrainis constituted $42 \%$ of the nursing workforce in the country. In October 2011, CHS governance was moved from the Ministry of Health to the University of Bahrain.

\section{Current situation}

Nursing education's mission is consistent with the Bahrain Economic Vision 2030 (8) as well as with Bahrain's Health Strategy, which aims to develop highly skilled healthcare professionals and improve delivery of quality healthcare. Nursing education is currently offered by two universities, the University of Bahrain, which is the main public university, and the Royal College of Surgeons Ireland - Medical University of Bahrain (RCSI-MUB), which is a private university. Both universities offer undergraduate and postgraduate programmes.

Over the past decades, the Nursing Division has evolved to become a reputable training hub in the Region. In August 1990, the CHS Nursing Division was designated as the first WHO Collaborating Centre (WHOCC) for Nursing Development in the Eastern Mediterranean Region (EMR). In June 1992, the CHS Nursing Division WHOCC was accepted as a full member in the Global Network of the WHO Collaborating Centres.

The First Global Network of WHO Collaborating Centres (WHOCC) for Nursing and Midwifery Conference was organized in March 1996 by the WHO Collaborating Centre for Nursing Development in Bahrain, in collaboration with Yonsei University WHO Collaborating Centre for Research and Training for Nursing Development in Primary Healthcare in Korea, which was the Secretariat of the global network then. The global conference was held in Bahrain under the theme 'Nurses and Midwives: Making a Difference'. Ever since its establishment, the CHS has endeavoured to function as a centre of excellence in nursing education.

The World Health Organization has played a vital role in developing human resources for health in Bahrain including nurses and midwives. Through the collaborative programme between the WHO Regional Office for the Eastern Mediterranean and the Ministry of Health, technical support was provided to CHS since its inception in transforming nursing education in Bahrain. In addition, over the years Bahrain has received many WHO designates from the Region who have undergone training programmes in various health fields, both tailor made and regular programmes.

The Gulf Cooperation Council (GCC) countries' Nursing Technical Committee adopted WHO recommendation to have one entry level into the profession and to limit categorization of nursing personnel. In response to this recommendation, Bahrain started the generic Bachelor of Science degree in nursing in 2003 as a requirement for entry into practice.

At present, nationals constitute $62 \%$ of the nursing workforce in Bahrain. CHS has been instrumental in meeting the country's need for nurses both at the general and the specialist levels, and 4329 nurses graduated from the College from 1978 to 2016. Moreover, 858 nurses graduated from the generic and the bridging nursing 
programmes from RCSI-MUB since its establishment in Bahrain in 2006.

\section{Enabling factors and strategies supporting transformation}

The following presents the strategic changes and the enabling factors that supported transformation of nursing education in Bahrain.

\section{Collaboration and partnership}

Responding to the demand for a reform of nursing practice, which in turn needed a reform in nursing and midwifery education, a strong triangulation between nursing practice, nursing education, and the community was established and formed the basis for adopting a collaborative approach to reform education in Bahrain. The context in which society and nursing interact was analysed, and beliefs and values about society's state of health, nursing profession, learning and teaching were identified. These made up the core concepts that constituted the conceptual framework for an all-encompassing curriculum reform and innovation in undergraduate and specialized nursing education programmes (3).

\section{Competency-based curriculum (CBE)}

Collaboration and partnership among all concerned continued along the path of nursing education reform, resulting in a Competency-Based Education (CBE), which aimed to produce competent nurses and midwives aligned with the demands of nursing practice and a changing society. The process for competency development was initiated early in 1984 and the curricula for all programmes were reviewed. Competencies were grouped under three domains: cognitive, affective, and psychomotor skills, while faculty strived to create measurable and observable outcomes that allowed for flexibility and innovation.

\section{Case-based learning (CBL) curriculum}

A review of nursing education strategy in 1995 was an outcome of the strategic plan for nursing reform in Bahrain (9). A curriculum planning task force was formulated in 1996 to spearhead a review of all curricula. Consensus was reached to adopt the Case-Based Learning (CBL) curriculum in 1996 and the CBL was fully implemented in 1998 (10). The cases used in the new reformed curricula were of real individual clients, families or community cases. The case-based character provided learners with an insight into the reality into the profession for their role as nurses, and it also fostered students' self-direction, problem solving and critical thinking abilities.

The CBL embedded the competencies and methodology of teaching and learning in 60 to 70 cases of common health problems in Bahrain, and these cases constituted the undergraduate nursing curriculum. The CBL called for a true partnership between practice and education and at all levels, from planning to implementation and assessment of learning. Adopting
CBL meant that students and tutors take an active participatory role in the whole teaching-learning process. Students, being true partners in learning, called for the introduction of 'student portfolios', which is a purposeful collection of student work accumulated over time. It reveals students' learning, achievement and development, and evaluates the strengths and weaknesses of their work. Thus, it became an effective way for students to think about how they could improve future work.

\section{Inter-professional learning}

Bahrain was a pioneer in adopting Inter-Professional Learning (IPL) initiatives. By the mid-1990s several courses were delivered jointly to students from different health science programmes; these included English language, anatomy and physiology, and basic life support. In 2003, colleges of nursing and medicine jointly planned and convened several workshops related to ethical issues faced in clinical practice. These initiatives were taken a step further to include more collaborative teaching and learning projects such as communication, leadership and management and conducting joint research seminars. (11).

\section{Information technology and E-learning}

In a true spirit of innovation, advanced information technology for teaching, learning and research was introduced. It provided faculty and students with access to the tools for the successful delivery and interaction between each other, and it enhanced the nursing curriculum implementation. Students were provided with a laptop and connectivity to a virtual learning environment. Training on the latest technology solutions to enhance faculty and students' communication and academic alliance were made available.

\section{Clinical teaching and learning}

Perhaps most dissatisfaction observed was with students' clinical competencies (12). The integration of clinical teaching and learning experiences for clinical situations, and the expectations of the community within the healthcare system, was ineffective. Taskforces were formulated to study the clinical teaching and learning aspect of the curriculum with strong liaison between education and nursing services. Several changes were introduced to enhance the quality of clinical learning, these included site preparation prior to commencing student teaching and learning and the preparation of registered nurses for a preceptorship role; this model ensured that students work directly with patients and the healthcare team.

Students were exposed much earlier to clinical learning and were provided with more responsibilities in varied clinical situations from simple to complex. Assessment methods were modified to reflect the expected course outcomes and aligned to the programme's terminal competencies. 
As a precursor to clinical placement, nursing education made huge advances in the establishment of 'Nursing Skill Laboratories' that adhere to an international standard, and provide a safe learning environment for students to attain psychomotor skills and clinical competencies.

\section{Approaches to funding nursing education}

\section{Tamkeen scheme}

Tamkeen (Arabic word meaning 'empowerment') is a semi-governmental organization established in 2006 as part of Bahrain's national reform initiatives and in line with Bahrain's economic vision (13). It is tasked with developing the public and private sector as key drivers of economic development and aims at creating employment opportunities, enabling nationals to further their skills and advance their careers in all sectors including health through scholarships, providing support for training and education and fostering creation of enterprises. Support is provided to both individuals and institutions.

The College of Health Sciences and the Royal College of Surgeons in Ireland partnered with Tamkeen as a source of funding towards attainment of professional certifications. To encourage Bahraini candidates to enter the private sector, the private health services provide written employment assurance to the candidates who wish to join their nursing workforce upon completion of their nursing studies. Tamkeen then provides sponsorships to these candidates to study nursing at the public and private universities in the country.

\section{Quality of education and accreditation}

Quality improvement in nursing education is within the context of the wider education reform project in the country, which aims to ensure quality of education at all levels within the country and is implemented by the Bahrain Education and Training Quality Authority(BQA), established as an independent authority in 2008 (14). Nursing education in Bahrain, both government and private, has received the confidence for the Bachelor of Science in Nursing (BSN) and Bridging RN (registered nurse)BSN programmes from the Higher Education Review unit at BQA. Both nursing institutions' BSN programmes are classified on the National Qualification Framework (NQF) scale at level 8. This NQF classification of qualifications is according to a set of criteria for specified levels of learning achieved. This is to improve the quality of education, transparency, access and progression. Graduates are expected to work in the nursing profession in the healthcare sector and they may also undertake postgraduate studies in healthcare-related specializations. The last report by BQA placed nursing and midwifery education at university levels in the top category of tertiary educational institutions in Bahrain.

\section{Research}

Education reform would have been deficient had it not been based on the spirit of inquiry and the nurturing of research culture. Varied means of inquiry were adopted right from the beginning of 1980 . These included gathering of expert opinion, use of nursing process, surveys, and literature search to understand current nursing practice. The concept of systematic thinking embedded in research was introduced in all nursing programmes. Research was introduced in its proper form in 1984 with the establishment of the BSN bridging programme and it became an essential concept in all specialty programmes. Students also learn to utilize research findings in delivering care as an evidence-based practice approach.

\section{Conclusion}

The last five decades have witnessed important developments in nursing and midwifery education in Bahrain. The increased demand to deliver high-quality nursing care to the citizens and residents in Bahrain required a transformation of nursing education. One of the key success factors in transforming nursing education in the country was using a systematic approach to develop a national education system that broadened the scope of nursing role and enabled graduates to think critically and respond to change in the healthcare system. One of the key strategies in the process was to bridge the gap between education and practice by putting mechanisms in place to actively engage the nursing services from the first stages of the educational programme planning to programme implementation and evaluation. Another strategy included the adoption of a reality case-based model in which nursing students bridge the gap between education and clinical practice from the early stages of their education

Technical support received from WHO over the years and collaboration and twinning with other regional and international educational institutions contributed to the reform of nursing education in Bahrain. Investment in the country's human capital included faculty development in nursing, enabling the health sciences educational institutions to respond to change. One of the key success factors in transforming nursing education in the country was visionary leadership and using a systemic approach to develop academic programmes in nursing and midwifery. To conclude, transformation of nursing education in Bahrain will continue to shape the future practice of nursing, respond to change in society and contribute to the improvement of health system performance and the provision of quality healthcare.

Funding: None.

Competing interests: None declared. 


\section{Transformation des programmes d'éducation en soins infirmiers : l'expérience de Bahreïn}

\section{Résumé}

La formation en soins infirmiers et obstétricaux a évolué de manière importante à Bahreïn; on peut noter, en particulier, la transformation qui s'est opérée depuis la création du Collège des sciences de la santé en 1976. Cet établissement a joué un rôle pionnier dans les programmes éducatifs nationaux destinés aux professions de la santé et a permis de satisfaire les besoins en matière de personnels infirmiers et de sages-femmes aux niveaux national et régional. La présente analyse a pour but d'examiner les stratégies qui ont permis de transformer la formation en soins infirmiers et d'y intégrer des modèles éducatifs contemporains. Les facteurs décisifs de cette transformation ont été l'élaboration d'un système de programme éducatif centré sur les étudiant(e)s et fondé sur les compétences; l'instauration, dans le programme d'enseignement, d'un équilibre entre les fonctions liées au maintien de la santé et les fonctions curatives du métier d'infirmier, ce qui a permis d'élargir le champ d'activité de ce rôle ; le développement du corps enseignant; la collaboration active entre services éducatifs et services de soins infirmiers dans la planification et la mise en œuvre des programmes d'enseignement; et les initiatives lancées pour financer l'éducation en soins infirmiers et assurer la qualité des programmes. En 1984, seuls $15 \%$ des postes exigeant une qualification minimale d'infirmier(-ière) agréé(e) étaient pourvus par des Bahreïnites. Cependant, la proportion de ressortissants nationaux dans les personnels infirmiers n'a cessé d'augmenter, et aujourd'hui les Bahreïnites représentent $62 \%$ des personnels infirmiers de leur pays. Ainsi, la transformation de la formation en soins infirmiers a été le pilier de la restructuration de la profession infirmière.

$$
\begin{aligned}
& \text { التحول في تعليم التمريض: خبرات من مملكة البحرين }
\end{aligned}
$$

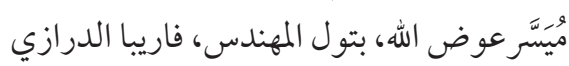

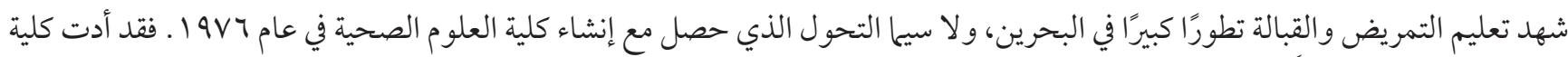

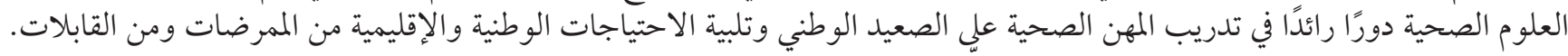

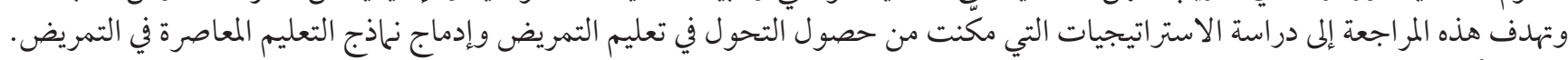

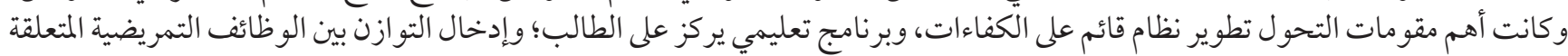

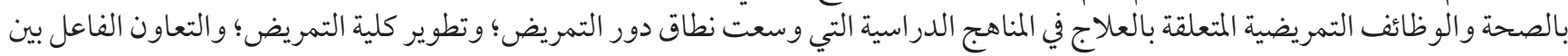

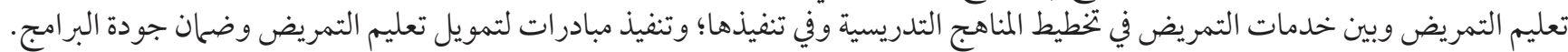

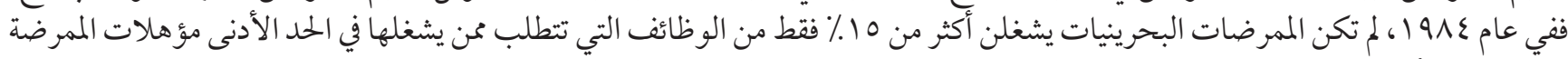

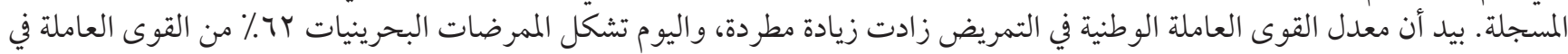

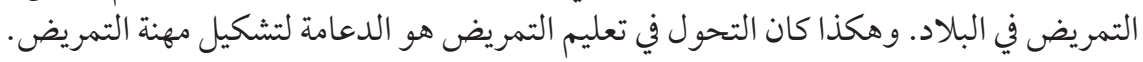

\section{References}

1. Kahatanie K. Nursing in Bahrain: historical overview. Unpublished paper presented at the 1oth Anniversary celebrations of the College of Health Sciences. Bahrain:1986.

2. Al-Darazi F. Current status and future trends in nursing education in Bahrain. Unpublished paper presented at the Intercountry meeting on nursing in the Eastern Mediterranean countries, 20-24 September 1987. Alexandria, Egypt: World Health Organization Regional Office for the Eastern Mediterranean:1988.

3. Kronfol NM, Affara FA. Nursing education in the Arabian Gulf: the Bahrain model. Int J Nurs Stud. 1982;19(2):89-98. https://doi. org/10.1016/0020-7489(82)90025-6 PMID:6921174

4. McGaghie WC, Miller GE, Sajid AW, Telder TV. Competency-based curriculum development on medical education: an introduction. 1978; Geneva: World Health Organization. Public Health Pap. (68):11-91. (https://www.ncbi.nlm.nih.gov/pubmed/664734 accessed 12 March 2018).

5. Affara F. Associate Degree nursing programme at the College of Health Sciences. Unpublished paper. College of Health Sciences. Bahrain: 1985 .

6. Affara A. Nursing Education in Bahrain: preparing for future practice.p.135. Unpublished paper presented at the 10th Anniversary celebrations of the College of Health Sciences; Bahrain:1986.

7. Abdulla, A. Update on faculty development training needs, Nursing Division, College of Health Sciences. Unpublished paper: Bahrain:1987.

8. Economic vision 2030 Kingdom of Bahrain-eGovernment Portal. (https://www.bahrain.bh/wps/portal/!ut/p/a1/o4_Sj9CPykssyoxPLMnMzovMAfGjzOI9_A3MDIosjLwMQkLdDBz9goo8fFw9jA2CzIEKIlEUGBu7AhWYmQeYh1kamVkYEKffwMjX2dDTBKjAlgfAwNHCKcgnxM3ZwMDdmEj9OIAjQfuDU_Pow_WjoJRh-gKsAJ8zIQpwu6MgNzQoosIzEwCLTo6c/dl5/d5/L2dBISEvZoFBIS9nQSEh/, accessed 11 March 2018). 
9. McElmurry B. Revision of nursing curriculum in Bahrain. A report of World Health Organization Regional Office for the Eastern Mediterranean. Alexandria: World Health Organization; 1995.

10. Uys L. Development of case-based curriculum for nursing Programmes. A report World Health Organization Regional Office for the Eastern Mediterranean. Alexandria: World Health Organization; 1998.

11. Suwaileh M, Gwele N. A curriculum for Interprofessional Learning. Uys L. and Gwele N. Curriculum Development in Nursing: process and Innovation. London: Routledge; 2005. p. 213. https://doi.org/10.4324/9780203313343_chapter_13

12. Al-Muhandis B. Clinical teaching and learning myths and challenges. Editorial. J Bahrain Med Soc. 2000;12(1).

13. Kingdom of Bahrain. Tamkeen (https://www.tamkeen.bh).

14. Kingdom of Bahrain. Education and training Quality Authority (http://www.bqa.gov.bh/ar/Pages/default.aspx). 